\title{
The Design and Empirical Analysis of Information Index for China Express Service Industry
}

\author{
Wu Haijian, Han Song \\ Institute of Information, Beijing Wuzi University, Beijing, China \\ Email address: \\ whjhn@163.com (Wu Haijian), songhan82@163.com (Han Song)
}

\section{To cite this article:}

Wu Haijian, Han Song. The Design and Empirical Analysis of Information Index for China Express Service Industry. International Journal of Business and Economics Research. Vol. 5, No. 4, 2016, pp. 123-126. doi: 10.11648/j.ijber.20160504.17

Received: March 14, 2016; Accepted: March 22, 2016; Published: August 6, 2016

\begin{abstract}
Based on the data of China's third economic census, the paper presents a statistical description of the developing level about the national express service industry information, which in four aspects from the using of computer, popularity of internet, the system of information management and e-commerce development. By the promoting path to "environment-basis-Application", it is designed the information indexes of the express service industry, meanwhile, three sub-indexes are measured and compared which about the environment, understructure and application between all provinces. In the end, suggestions were put forward to the express service industry.
\end{abstract}

Keywords: Express Service Industry, Information Level, Index, Statistical Evaluation

\section{Introduction}

Flourishing quickly in the past 10 years in China, the e-commerce has promoted a high development accompanying expansion of the express service industry. From the concept, "the express service industry " originally belong to "the post industry " category (national economic industry classification 4754-2011 GB/T), which is a kind of faster service will be some letters or information delivery to the recipient's hand service; and the booming e-commerce, promote the express and "logistics" cross-border integration (Xu Zhenyu, 2014), thus great change made in express service industry connotation. Many logistics companies began to get involved in the express business, many express companies are building logistics system. In this case, the express service information technology has become the core of the courier company to enhance the service capabilities, boost up the competitive edge. At present, the level of information technology in the large $r$ enterprises, directly determines the level of their own services, development scale, market performance and other aspects, courier service transformation and upgrading must take the road of information.

Express service information is the use of modern information technology to the courier company to produce all or part of the information collection, classification, transfer, summary, identification, tracking, query and a series of processing activities, in order to achieve the flow of goods control, thereby reducing the cost and improve economic performance of the management activities. Express service information is the inevitable requirement and the cornerstone of the development of modern express service industry, its role is mainly reflected in the improvement of efficiency and standardization management.

According to the data of China's third economic census and China statistical data base, this paper comprehensively describes the development level of the national express industry information, and puts forward the design idea and method of the information level index, measuring and analysis have been given to various aspects of the information.

\section{Status Quo of Information Level in China's Express Service Industry}

\subsection{The Rate of Computer Using Is High in Express Enterprise}

Based on the data of 436 key enterprises, all of them had applied the computer in their process production and management. By the end of 2012, the number of computers is 
106421, which used in the process of production and operation in express enterprises, and the average is 244 using in each enterprise. From the regional point of view, each enterprise has been more using computers in Beijing, Guangdong, Tianjin, Shanghai, Jilin, among which is reached 901 units in Beijing.

\subsection{Management of Informatization Focus on the Management of Finance and Logistics}

The number of all enterprises is reached 427 , accounting for $98 \%$ of the total, which in the information management on the internal production and operation activity. Data shows that the information management activities of the express enterprise, mainly for financial management, sales and management, production management, logistics and distribution management, customer relationship management and human resource management, financial management and logistics information and logistics management information technology, the number of enterprises, respectively, $79.59 \%$ and $71.56 \%$.

\subsection{The High Rate of Internet Prevalence}

In the production and operation of the use of the Internet has reached $99 \%$. Through the Internet to carry out the production and business activities, covering almost all aspects, but there is a little difference between the various types. The proportion of enterprises that receive e-mail via the Internet is the largest, reaching $91 \%$; the use of Internet banking accounted for $72 \%$; the use of the Internet to provide products, and the connection of states and other financial services accounted for a small proportion.

\subsection{Lower of the Construction of the Website}

Based on the data provide from 436 key courier companies, the proportion of the website of the company reached $62 \%$, and through the Internet for the enterprise to promote themselves about $79.6 \%$. But through its own independent website for the promotion of the enterprise is only $52.45 \%$, and through the search engine and micro blog to promote the proportion of enterprises is lower. The information talents is the support of information technology. The national companies have full-time engaged in information technology staff of the enterprise, the proportion is $79.13 \%$.

\subsection{Slower of Electronic Commerce Development}

In the year of 2012 , the enterprises is 23 which receiving goods or ordering services from e-commerce sales, accounting for 5.3\%; annual e-commerce sales amount (excluding VAT) is 3345 million yuan, and the $94 \%$ is B2B. There are 11 enterprises which through the Internet to send a commodity or service orders, accounting for $2.5 \%$.

The data shows that the level of e-commerce in express enterprise is relatively low and the development is very slow. Express enterprise's e-commerce development, will become a major development opportunities in the express service industry.

\section{The Index of Express Industry Information Level Designed}

\subsection{Evaluation Index System of Informatization}

It is the primary problem which established the system of information measurement. Only the establishment of the information system, it is possible to understand the level of express information, the development process, the existence of the problem, to understand the level of information and structure of the whole country to express the impact of the development of the whole country. In recent years, the government's policy support for the development of information technology is an important driving force for the development of information technology. A good information environment, which is conducive to the efficient use of investment funds in the development of information technology, the smooth progress of information activities, the training and development of information technology, same as the dissemination of information and communication, the most important factor in the process of promoting. It is need supporting not only the strong environment, but also the original material - personnel and equipment based on information to contact the courier industry, for the application of information technology in the delivery platform. Information only applies to the specific operations of the courier companies, in order to make a contribution to its development.

To sum up, based on its driving path of the evaluation index system of the level of express information, there are three aspects about the environment - the basis - the application, included three first level indicators, seven secondary indicators and fourteen last degree indicators.

\subsection{Analysis of the Results About the Index System}

\subsubsection{Total Index Analysis}

According to the index system of the level of express information, this paper estimates the score of the 31 regions of the country, and then gets the score of the three levels of index, based on the initial value, index was calculated which of the information environment, the information based and the application of the information technology. In order to facilitate comparison, the biggest score, 100 was choiced as the standard city, the other region to adjust the ratio of the score, the score of the express information level.

From the total index, the top three of the region were Beijing, Shanghai and Guangdong, which means the value of the above 90 points. The three ranked regions were Tibet, Ningxia and Shanxi. Thus, on the whole, the national regional express information level is characterized unbalanced development, most of the city still has a large room for improvement.

\subsubsection{Environmental Index Analysis}

Information environment reflects the level of a region, under the support of government, education and other aspects to enhance the level of service and support for the express 
service information. Estimates show that good information policy, education environment and atmosphere is an important condition for promoting the level of express information.

It can be seen from the measurement data, all provinces in the information based on the high score gap. It can be divided into three intervals: the score in the region of 60 points more than in Beijing, Shanghai, Tianjin, Guizhou and Jiangsu, Qinghai and Guangdong in the following 10 points, the other areas of the average score of 15 to 50 points. In terms of the ranking similar to the total index, Beijing and Shanghai are still ranked in the top two. Investigate its reason, from the raw data, Beijing and Shanghai in the investment in fixed assets ratio of information industry and the university students have obvious advantages, the mainly reason is actively promote the investments in the information technology in Beijing and Shanghai in recent years, and colleges and universities gathered, outstanding talent as well.

\subsubsection{Foundation Index Analysis}

The foundation level of information reflects in the field of human strength and equipment investment in the mainstream application.

From the measurement data, the scores are over 100 points in Qinghai, Guangxi and Beijing, Tibet's mark is the lowest score which impacted the total index of Tibet. Qinghai and Guangxi are relatively backward in the information environment and information technology applications, otherwise the top two on the information foundation, it is in the overall index of information to make an important contribution. This shows that Qinghai and Guangxi are very focused on personnel and equipment information technology. And Henan in the information level of the total index of the middle ranking, here is ranked in the bottom second, the overall strength of the development of Henan express information, information technology based on its weak link. Overall, the regional information based on the basis of the score is not concentrated, but the distribution is relatively uniform, and there is no obvious echelon structure.

\subsubsection{Application Index Analysis}

It can hardly create value unless the development of information technology applied, therefore, it is an important aspect, the application of information technology, to measure the level of information technology. Three aspects are included in the application of information technology: information management, information management and electronic commerce.

From the measurement data, it is known that the scores difference relatively large from the application and the level of informatization, Beijing's information technology application in the middle level, the reason is mainly the Beijing express industry in e-commerce sales and procurement of backward due; Hainan is the first in the application of information technology, this is mainly because of its information management and e-commerce sales development highlights. As a whole, there are less obvious echelon structure, but there is a big gap from the first to the last in the application of information technology regional development is not balanced.

\section{Suggestions for Accelerating the Development of the Informatization}

First, strengthen the information management of express delivery industry. Most of the enterprises have been informatization which on the financial management and logistics management in, however, it were less than $50 \%$ in the human resource management and customer relationship management. Therefore, we should strengthen the information management in the express industry, especially pay much attention to the management of human resource and customer relationship.

Second, accelerate the development of electronic commerce in the express industry. At present, a few companies carry out their business through e-commerce, it shows extremely slow on the development of e-commerce. In the development of e-commerce today, to accelerate the development of e-commerce in the express delivery industry will be an important opportunity for the development of the express delivery industry.

Third, the balanced regional express industry information construction. From the analysis of the level of information technology in the express industry, it can be seen that the level of informationization in Beijing, Shanghai and Guangdong is relatively high, and the level of information in Shanxi, Ningxia and Tibet is lower. Regional express information level shows unbalanced development characteristics, most of the city still has a large room for improvement. It will be in favor of the development of the industry which work constructed by the balanced regional express industry.

\section{References}

[1] Application of [J]. technology and logistics information technology to boost. 2013. forward Ann Husheng express industry (7): 96-98.

[2] $\mathrm{Li} \mathrm{Li}, \mathrm{Bu}$ Xinhua, Wang Hezhen. Research on the impact of the development of the 2012 express industry on the service level of [J]. Information Systems Engineering (6): 117-118.

[3] Cui Bin, Yue Rao, Chen Ping. 2015. on the express recipient right system perfecting $[\mathrm{J}]$. legal system and social protection of personal information (14): 44-46.

[4] National Bureau of Statistics (4754-2011 http://www.stats.gov.cn/tjsj/tjbz/hyflbz/ [EB/OL].

$\mathrm{GB} / \mathrm{T})$

[5] Liu Lu, Gu Jiuchun., 2015. express logistics tracking on [J]. computer application model and application of information exchange (9): 2712-2715.

[6] Jia Ruiting. 2015. information technology to become the core of the express delivery industry IT [J]. times weekly (1): 10.

[7] Liu Dan. 2014. China's e-commerce and express industry collaborative development path [J]. technology economy (2): 45-49.

[8] The development trend of the era of big data Xingxin Nie. 2014. FedEx [J]. logistics technology (12): 134-135. 
[9] Wang Zimin. 2012. economic growth - Internet development and the relationship between the express industry research [J]. Journal of Beijing Jiaotong University (7): 63-69.

[10] Wei Guangxing. 2010. based on information entropy and gray correlation method of express enterprise competitiveness research $[\mathrm{J}]$. science and Technology Management Research (7): 116-119.

[11] Xu Zhenyu. 2014. e-commerce and express industry cross-border business agent [J]. business era (15): 64-67.

[12] Xiao Lianjun. 2003. civil aviation express integrated management information system CAEMIS [J]. China Civil Aviation (8): 56-58.
[13] The relationship between the value and contribution of logistics information express industry human capital study [J]. logistics engineering and management based on Yan Yan. 2015. (8): 30-32.

[14] Zheng Xiaoting. 2009 express business non - counter for risk analysis and information control [J]. China logistics and procurement (9): 74-75.

[15] Zhang Bailong, Zhang Yong. 2015. information technology transformation to promote the integration of [J]. China Post (9): 20-21. 